\title{
PUSAT PEMANFAATAN DAN KONSERVASI TAILING KUTO PANJI
}

\author{
Steffi Setiawan ${ }^{1)}$, Maria Veronica Gandha ${ }^{2)}$ \\ ${ }^{1)}$ Program Studi S1 Arsitektur, Fakultas Teknik, Universitas Tarumanagara, \\ steffisetiawan.arch@gmail.com \\ ${ }^{2)}$ Program Studi S1 Arsitektur, Fakultas Teknik, Universitas Tarumanagara, mariag@ft.untar.ac.id
}

Masuk: 04-07-2021, revisi: 12-08-2021, diterima untuk diterbitkan: 23-10-2021

\begin{abstract}
Abstrak
Tambang timah di Provinsi Bangka Belitung sudah sejak tiga abad lalu di eksploitasi, kegiatan eksploitasi ini mengakibatkan terganggunya lanskap dan menimbulkan dampak lingkungan. Dampak lingkungan yang ditimbulkan adalah peningkatan suhu, dan kelembaban. Lanskap pada area bekas tambang timah memperlihatkan dua bentuk permukaan, yaitu: tailing dan kolong. Tailing merupakan sisa dari pencucian mineral timah dan kolong berbentuk seperti kolam atau danau kecil. Struktur lapisan tanah pada area bekas tambang timah tidak seperti struktur tanah pada umumnya, lapisan tanah bagian atas atau top soil pada area bekas tambang timah umumnya sudah hilang, dan kesuburan tanah menjadi rendah dengan tingginya kadar fraksi pasir. Area yang sudah di eksploitasi harus direklamasi dan direvegetasi agar aman untuk dikunjungi. Salah satu limbah dari kegiatan tambang timah yaitu tailing, maka menjadikan Provinsi Bangka Belitung sebagai produsen hamparan tailing, tailing tersebut dapat dimanfaatkan kembali menjadi bahan pembuatan batako, namun sebelum diolah menjadi bahan batako, perlu dilakukan pemisahan tailing dengan bahan yang berbahaya menggunakan magnetic separator sehingga aman untuk menjadi salah satu bahan pembuatan batako. Untuk penelitian lebih lanjut pemanfaatan lain dari area bekas tambang timah, maka diperlukannya tempat konservasi. Selain itu, menjadi tempat rekreasi dan edukasi berupa elevated trails yang mengitari area reklamasi tambang timah dengan sekelilingnya terdapat area bekas tambang timah, tambak udang yang sebelumnya adalah area bekas tambang timah, dan tropical rainforest. Pendekatan desain dalam perencanaan ini adalah dengan menjadikan rumah adat Suku Lom sebagai acuan dari penerapan arsitektur tropis. Melalui pendekatan tersebut menghasilkan pengudaraan alami dari bentuk gubahan baru. Selain itu konsep perancangan ini juga menambahkan sun shading dan courtyard sebagai bagian dari arsitektur tropis.
\end{abstract}

Kata kunci: bekas tambang timah; konservasi; revegetasi; reklamasi; rumah adat Suku Lom

\begin{abstract}
The tin mining in Bangka Belitung Province has been exploited for the past three centuries, this exploitation activity disrupts the landscape and causes environmental impacts. The resulting environmental impact is an increase in temperature and humidity. The landscape in the ex-tin mining area shows two surface forms, namely: tailings and underneath. Tailings are the residue left over from leaching of tin minerals, and underneath are shaped like ponds or small lakes. The structure of the soil layer in the former tin mining area is not like the soil structure in general, the topsoil in the former tin mining area has generally been lost, and the soil fertility is low with high levels of the sand fraction. Areas that have been exploited must be reclaimed and revegetated, so that it is safe to visit. One of the wastes from tin mining activities, namely tailings, has made Bangka Belitung Province a producer of tailings, the tailings can be reused as material for brick making, but before processed into brick material, it is necessary to separate the tailings from hazardous materials using a magnetic separator so that it is safe to become one of the brick-making materials. For further research on other uses of the ex-tin mining area, a conservation area is needed. Other than that, it is a place of recreation and education, in the form of elevated trails that surround the tin mine reclamation area with surrounding areas of former tin mines, shrimp pond that was
\end{abstract}


previously a former tin mining area, and tropical rainforest. The design approach used in this planning is to make the traditional house of the Lom Tribe as a reference for the application of tropical architecture. Through this approach, it produces natural ventilation of the new composition. In addition, this design concept also adds sun shading and courtyard as part of tropical architecture.

Keywords: ex-mining site; conservation; revegetation; reclamation; the traditional house of Lom Tribe

\section{PENDAHULUAN}

Menurut Pemerintah Daerah Kepulauan Bangka Belitung (2010), luas total kuasa penambangan timah di Pulau Bangka mencapai 374 ribu ha atau 35\% dari total luasan daratan Pulau Bangka yang sebagian besar dimiliki oleh PT Timah dan PT Kobatin, sisanya merupakan milik perusahaan swasta atau rakyat (Subardja, D., Kasno, A., Suryani, E., p. 370). Dan disampaikan oleh Ai Dariah et al. (2010), luas areal penambangan yang telah diberi izin eksploitasi secara nasional sampai tahun 2009 mencapai 2,2 juta ha. Berdasarkan dari Tanpibal dan Sahunalu (1989); Dubey et. al. (2006); Simarmata (2007); Sitorus et al. (2008), kegiatan penambangan timah menghasilkan dampak positif untuk perekonomian, namun mengakibatkan dampak negatif terhadap lingkungan dan lanskap karena menyebabkan hilangnya flora dan fauna, penurunan kesuburan tanah, menyebabkan erosi, penurunan kualitas air dan menghancurkan komunitas mikroba, kehilangan biodiversitas, berkurangnya habitat hewan liar, dan degradasi daerah penampung air (Sutono, S., Haryati, U., \& Agus, F., 2020, p. 100). Lahan-lahan bekas tambang sebagian besar belum atau tidak direklamasi dan dibiarkan terlantar, atau pernah direklamasi namun ditambang kembali secara ilegal oleh masyarakat setempat (Subardja, D., Kasno, A., Suryani, E., p. 370).

Maka lahan-lahan bekas tambang timah harus direklamasi untuk membenahi permukaan lingkungan yang rusak dan dapat melakukan pemanfaatan tailing hasil bekas pengolahan tambang menjadi bahan dasar industri bangunan, dimana bertujuan untuk mengurangi limbah hasil eksploitasi tamban. Tujuan lain adalah sebagai tempat mengedukasi, dimana terdapat elevated trails yang mengitari sekitar untuk melihat bagaimana perubahan lingkungan sebelum dan setelah ditambang, lalu penyelesaian setelah ditambang yang berupa tambak udang.

\section{KAJIAN LITERATUR}

\section{Karakteristik lahan bekas tambang timah}

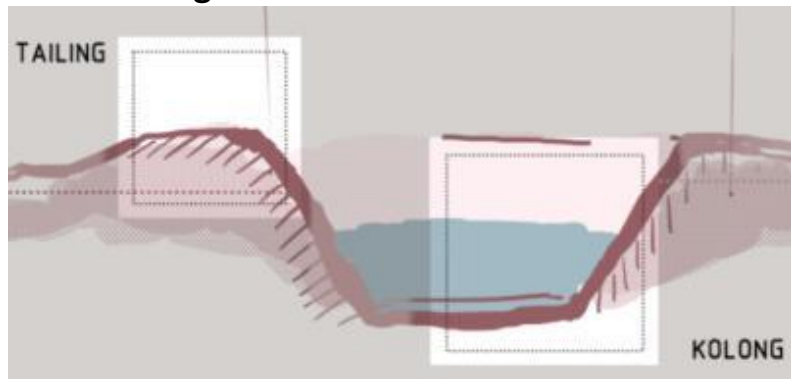

Gambar 1. Lanskap Area Bekas Tambang Timah

Sumber: Dokumentasi Pribadi, 2021

Menurut Sukarman dan Gani (2017), kegiatan penambangan, terutama yang terbuka, menyebabkan: 1) lubang bekas tambang yang biasanya berisi air (kolong atau void), 2) tumpukan hasil galian (tanah pucuk yang membentuk wilayah berombak, 3) tumpukan hasil galian di bagian bawah tanah pucuk (overburden), 4) tumpukan hasil proses pencucian bahan yang mengandung timah (tailing) (Sutono, S., Haryati, U., \& Agus, F., 2020, p. 99). 


\section{Reklamasi Tambang Timah \\ Penataan Lahan}

Melakukan penataan area bekas tambang timah: (1) rekonstruksi bentuk lahan (reshaping), dan (2) membentuk saluran drainase. Pembentukan ulang bentuk lahan dari bekas tambang timah agar mendapatkan lereng yang stabil dengan potensi longsor dan erosi yang rendah serta layak untuk direvegetasi. Pembentukan kembali bentuk lahan disesuaikan dengan kondisi topografi dari area bekas tambang timah. Lahan bekas tambang timah yang berbentuk tidak beraturan maupun tidak merata (berlubang, atau mempunyai lereng dengan kemiringan yang relatif curam) harus dilakukan penataan agar stabil sehingga potensi terjadinya longsor dan erosi menjadi rendah (Direktorat Jenderal Pengendalian Pencemaran dan Kerusakan Lingkungan, 2016).

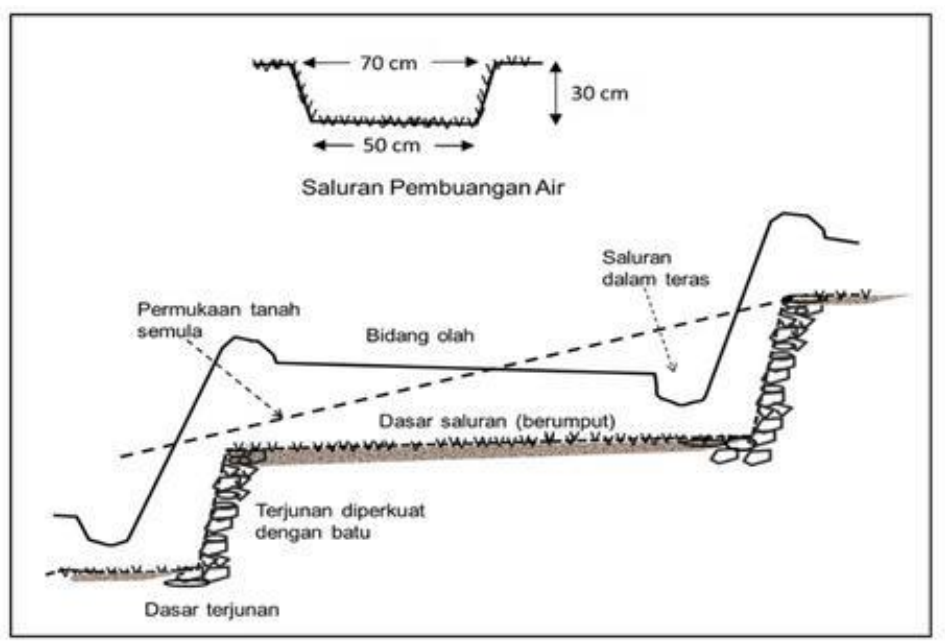

Gambar 2. Penampang Teras Bangku

Sumber: Direktorat Jenderal Pengendalian Pencemaran dan Kerusakan Lingkungan, 2016

Berikut adalah yang perlu diperhatikan dalam pembentukkan teras bangku: (1) Bidang olah dibuat miring ke arah saluran dalam dengan kemiringan $\pm 1 \%$, (2) Tanah pucuk yang semula di urug di suatu tempat tertentu, ditaburkan kembali secara merata di atas bidang olah yang telah terbentuk, (3) Pada ujung teras bagian luar (bibir teras) perlu dibuat guludan dengan tinggi 20 $\mathrm{cm}$ dan lebar $30 \mathrm{~cm}$, (4) Di bagian dalam teras dibuat saluran dengan lebar $20 \mathrm{~cm}$ dan dalam 10 cm (Direktorat Jenderal Pengendalian Pencemaran dan Kerusakan Lingkungan, 2016).

\section{Revegetasi}

Kegiatan revegetasi atau penanaman kembali bertujuan untuk memulihkan ekosistem yang sudah rusak, dapat dilakukan setelah kegiatan penataan area bekas tambang timah dan penyebaran tanah pucuk atau top soil telah selesai. Tahapan kegiatan revegetasi adalah sebagai berikut: (1) Persiapan lapangan, (2) Pengadaan bibit dan persemaian, (3) Pelaksanaan penanaman (Direktorat Jenderal Pengendalian Pencemaran dan Kerusakan Lingkungan, 2016). Berdasarkan dari hasil penelitian, tanaman yang mampu hidup pada lahan bekas tambang timah adalah Karet dengan persentase hidup sebesar 31.34\%, Akasia sebesar 33.64\%, dan Sengon sebesar 35.02\%, maka disimpulkan tanaman pionir yang cocok yaitu Sengon (Syachroni, S. H., Rosianty, Y., \& Samsuri, G. S., 2019).

\section{Pemanfaatan limbah tailing menjadi bahan batako}

Saat ini, limbah hasil pengolahan bijih atau tailing dengan hasil penelitian dan kemajuan teknologi dapat dimanfaatkan menjadi bahan bangunan. Pengembangan bahan bangunan dari tailing dapat memecahkan masalah lingkungan, dimana produk ini dapat dikategorikan menjadi bahan bangunan ekologis (Riogilang, H. dan Halimah Masloman, 2009). Batako merupakan 
bahan bangunan yang berupa bata cetak yang terbuat dari pasir, semen Portland dan air yang ukurannya hampir sama dengan batu bata. Berdasarkan pengujian batako menggunakan bahan tailing, persentase penyerapan air berada di bawah syarat maksimum yang menandakan daya serapnya tidak melewati ambang batas, sehingga baik untuk digunakan menjadi bahan konstruksi bangunan (Sandy, B. D. A., Guskarnali, G., \& Mahardika, R. G., 2019).

\section{METODE PERANCANGAN}

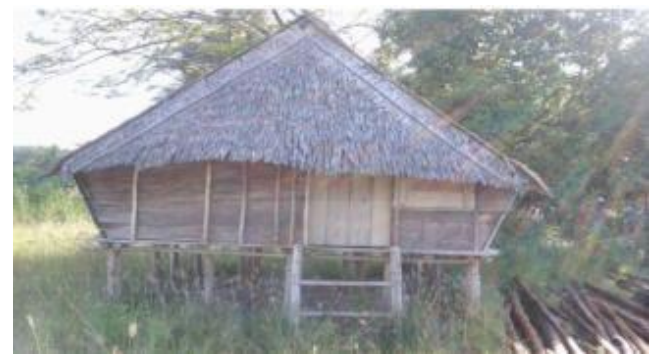

Gambar 3. Rumah Adat Suku Lom Sumber: Janawi, 2015

Pertama melakukan pengumpulan data dan menganalisa kondisi eksisting tapak secara solid atau void, tata fungsi lahan, hirarki jalan, elemen lunak dan keras sebagai data dasar perancangan. Dan metode perancangan yang digunakan dalam desain area pengolahan tailing dan konservasi ini adalah dengan menganalisa rumah adat Suku Lom sebagai acuan arsitektur tropis. Lalu diadaptasi ke bentuk yang baru atau sesuai dengan pembentukan desain. Selain itu, menambahkan penerapan arsitektur tropis pada perancangan seperti courtyard dan sun shading.

\section{DISKUSI DAN HASIL}

\section{Kondisi eksisting tapak}

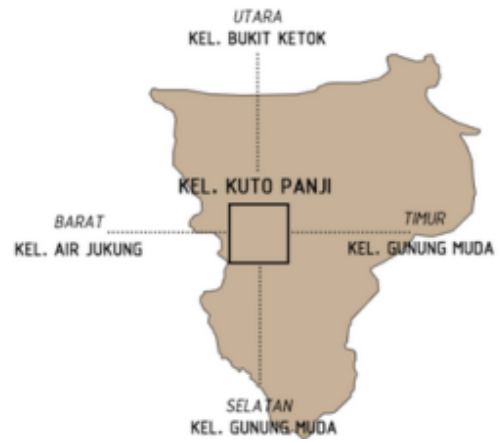

Gambar 4. Letak Tapak di Kecamatan Belinyu

Sumber: Dokumentasi Pribadi, 2021

Letak tapak berada pada area pertambangan timah di Kelurahan Kuto Panji, Kecamatan Belinyu, Kabupaten Bangka, Pulau Bangka, Provinsi Bangka Belitung. Tapak pada Kelurahan Kuto Panji berbatasan wilayah Barat dengan Kelurahan Air Jukung, sebelah Timur dan Selatan dengan Kelurahan Gunung Muda, dan sebelah Utara dengan Kelurahan Bukit Ketok. Letak tapak mempunyai iklim tropis dengan suhu cenderung panas. 


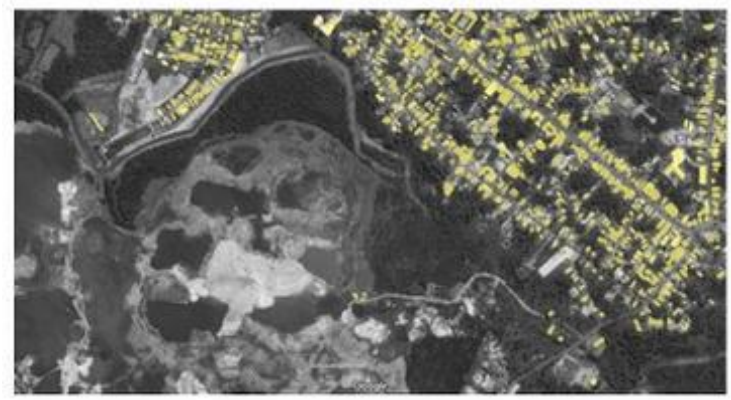

Gambar 5. Solid atau Void

Sumber: Dokumentasi Pribadi, 2021

Bagian solid terlihat pada gambar, tidak berada di bagian area pertambangan timah. Sedangkan bagian yang dominan solid terpisah dengan bagian area pertambangan. Bagian solid pada bagian hunian mempunyai bagian-bagian yang terdapat void.

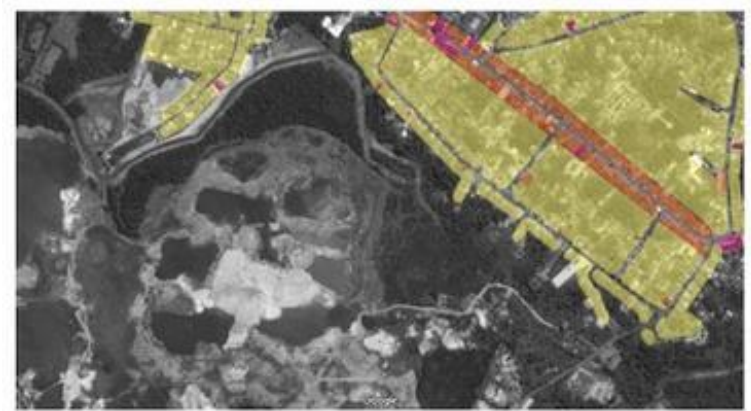

Gambar 6. Tata Fungsi Lahan

Sumber: Dokumentasi Pribadi, 2021
PERUMAHAN

PERDAGANGAN

/CAMPURAN

FASUITAS PELAYANAN

UMUM DAN SOSIAL

Pada bagian jalan Mayor Syafrie Rachman yang merupakan jalan penghubung BelinyuSungailiat mempunyai tata fungsi lahan sebagai perdagangan atau campuran yang berwarna oren. Pada bagian belakang tata fungsi lahan perdagangan atau campuran didominasi oleh fungsi perumahan. Diantara itu terdapat beberapa menjadi fungsi fasilitas pelayanan umum dan sosial.

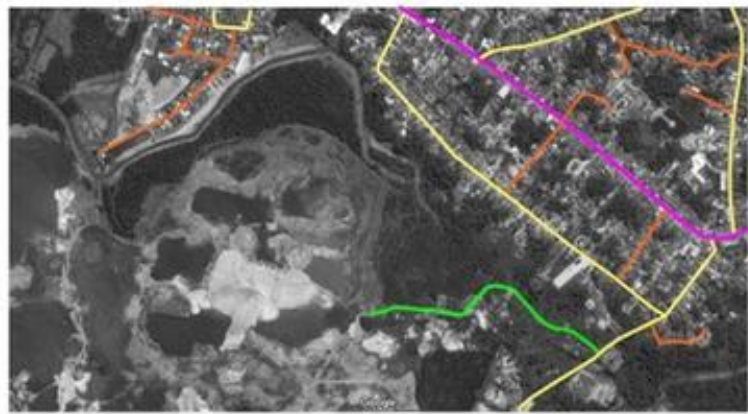

Gambar 7. Hirarki Jalan
KOLEKTOR PRIMER

LOKAL

LINGKUNGAN

LINGKUNGAN

(JALLAN KE AREA PERTAMBANGAN)

Sumber: Dokumentasi Pribadi, 2021

Jalan kolektor primer merupakan jalan Mayor Syafrie Rachman, jalan yang menghubungkan Belinyu-Sungailiat. Akses menuju tapak merupakan jalan dengan hirarki jalan lingkungan, jalan yang diperuntukkan untuk aktivitas tambang pada umumnya. Belakang jalan kolektor primer didominasi jalan lokal atau lingkungan yang menghubungkan ke hunian. 


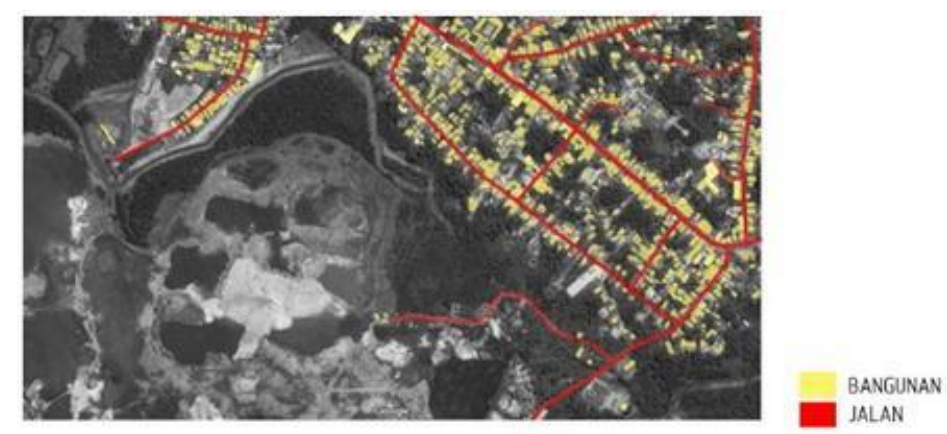

Gambar 8. Elemen Keras

Sumber: Dokumentasi Pribadi, 2021

Pembangunan jalan dan bangunan lebih menjauhi area tambang timah. Bagian elemen keras hanya sebatas jalan dan bangunan yang mendukung area tambang yaitu akses masuk ke area dan bangunan penjaga tambang. Pembangunan jalan dan bangunan lebih cepat di bagian jalan kolektor primer atau jalan yang menghubungkan Belinyu-Sungailiat.

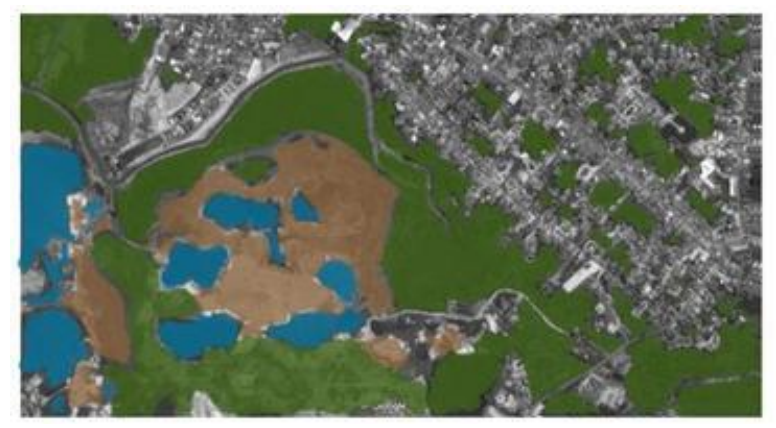

Gambar 9. Elemen Lunak

Sumber: Dokumentasi Pribadi, 2021
LOKASI VEGETASI

LOKASI KOLONG

LOKASI TANAH

Pada gambar diatas, terlihat vegetasi menjadi pemisah antara area tambang timah dengan area pemukiman warga. Pada area tambang cukup banyak lubang atau kolong berisikan air bekas tambang. Beberapa kolong pada gambar diatas sudah menjadi area tambak udang.

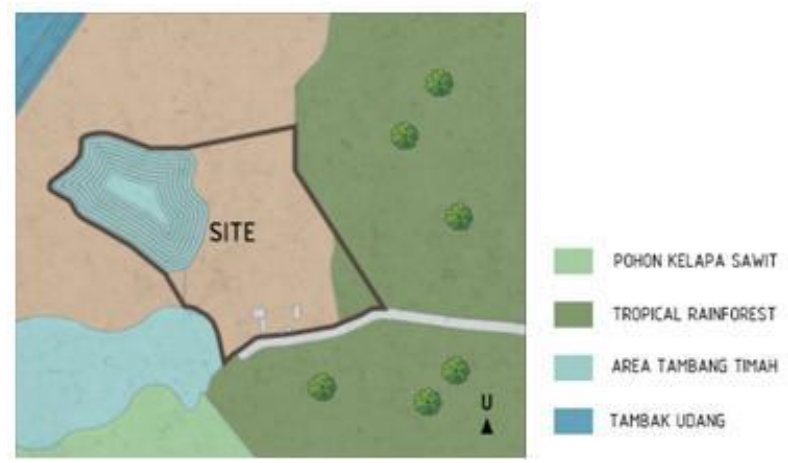

Gambar 10. Eksisting Sekitar Tapak

Sumber: Dokumentasi Pribadi, 2021

Eksisting tapak terdiri dari area tambang timah, lahan kosong, rumah penjaga, dan sebagian kecil tropical rainforest. Tapak berada tepat pada akses eksisting menuju ke area tambang timah. Pada bagian Barat, tapak bersebelahan dengan tropical rainforest, pada bagian Timur, tapak bersinggungan dengan area tambang timah. 


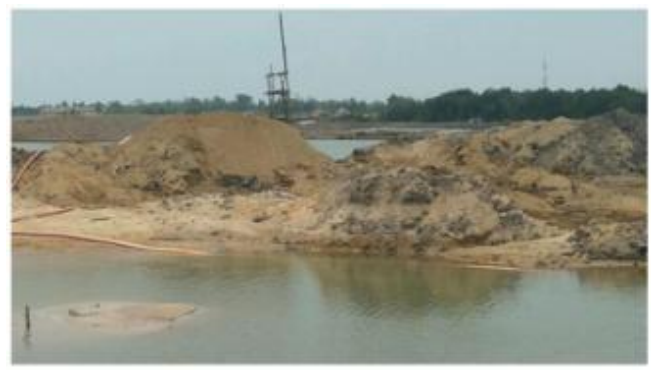

Gambar 11. Kolong Area Tambang Timah pada Tapak Sumber: Dokumentasi Pribadi, 2021

Keadaan area tambang timah yang berada di tapak berupa kolong dan tailing, tanpa adanya vegetasi, dan kehilangan top soil. Terlihat satu warga yang masih melakukan penambangan. Dari hasil wawancara dengan warga, kolong yang berada di tapak memiliki kedalaman 13 meter. Di sekitar tapak, beberapa tambang timah sudah direklamasi menjadi tambak udang.

\section{Konsep dan desain}

Program yang dipilih pada desain perancangan ini untuk menanggapi salah satu limbah kegiatan tambang, yaitu tailing, dengan mengusulkan perencanaan tempat proses pengolahan tailing menjadi batako. Salah satu prosesnya adalah memisahkan bahan yang berbahaya dari tailing agar aman untuk pemanfaatan kembali. Fungsi lain adalah sebagai tempat konservasi, dimana dapat menjadi tempat untuk mencari penggunaan kembali ke bentuk yang lain.

\section{Rehabilitasi area tambang timah}

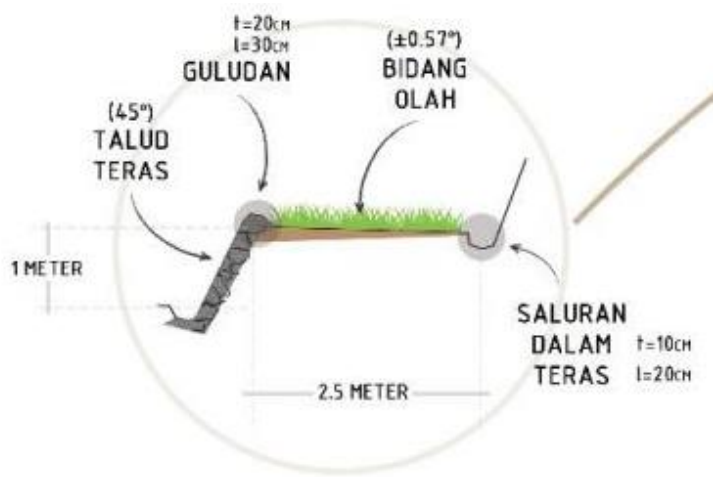

Gambar 12. Detail Pembuatan Teras Bangku Sumber: Dokumentasi Pribadi, 2021

Berikut penjelasan pembuatan teras bangku pada eksisting tapak yang merupakan area bekas tambang timah agar tidak curam: (1) Teras bangku mempunyai bidang olah dengan lebar 2.5 meter, tinggi 1 meter, dan dapat ditanami rumput pionir (2) Talud teras mempunyai kemiringan $45^{\circ}$ dan memakai batu-batuan, (3) Saluran dalam teras mempunyai tinggi $10 \mathrm{~cm}$ dan lebar 20 $\mathrm{cm}$. 


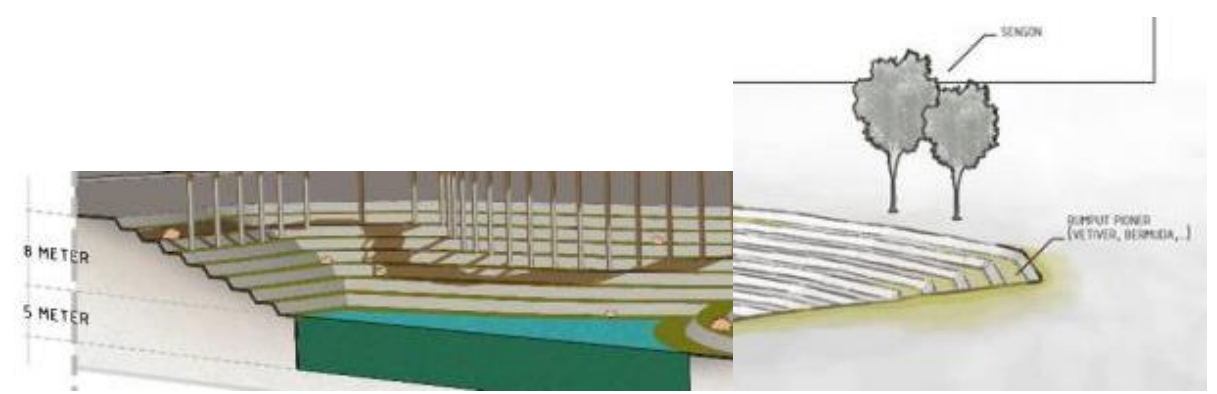

Gambar 13. Aplikasi pada Tapak yang Direhabilitasi

Sumber: Dokumentasi Pribadi, 2021

Kedalaman eksisting kolong pada area bekas tambang timah adalah 13 meter. Pada eksisting kolong pada area bekas tambang timah dibentuk teras bangku. Teras bangku yang dibentuk mempunyai total ketinggian 8 meter dan sisa 5 meter menjadi kolam. Tiap teras bangku mempunyai ketinggian 1 meter. Tanaman pioner yang digunakan untuk revegetasi adalah pohon sengon dan rumput vetiver sebagai cover crop. Tanaman ini mampu hidup di area bekas tambang timah yang direklamasi.

Acuan desain rumah adat Suku Lom

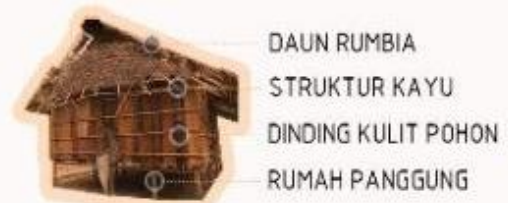

Gambar 14. Bentuk Dasar Rumah Adat Suku Lom

Sumber: Dokumentasi Pribadi, 2021

Konsep yang digunakan dalam desain perancangan Pusat Pemanfaatan dan Konservasi Tailing Kuto Panji ini adalah dengan melakukan pendekatan desain melalui rumah adat Suku Lom yang diadaptasi ke bentuk baru. Rumah adat Suku Lom merupakan rumah yang berbentuk sederhana beratapkan atap tropis dengan penutup atap daun rumbia dan struktur atap kayu. Bentuk dasar rumah adat Suku Lom memiliki atap tropis dengan kemiringan di kedua sisi yang sama. Rumah adat tersebut berupa rumah panggung. Bentuk rumah Suku Lom yang beradaptasi sudah memakai atap dengan penutup atap beragam, mulai dari lembaran metal atau keramik.

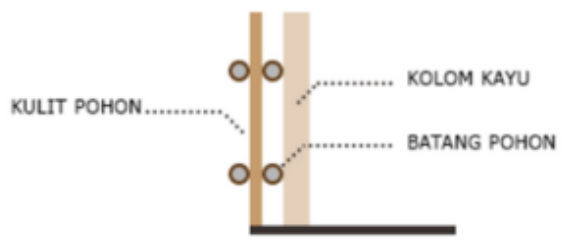

Gambar 15. Struktur Dinding Rumah Adat Suku Lom Sumber: Dokumentasi Pribadi, 2021

Dinding rumah adat Suku Lom menggunakan kulit pohon, dengan penggambaran struktur dimana kulit pohon diapit oleh kedua batang pohon yang bersandar ke kolom kayu. Bentuk kolom berbentuk bulat. Terlihat pada gambar, lantai rumah Suku Lom menggunakan susunan 
batang kayu yang berbentuk bulat dengan bentuk yang berbeda dan terdapat jarak sehingga udara dapat bebas masuk. Bagian atas tidak tertutup plafon, berbentuk terbuka, dapat terlihat struktur atap yang sederhana. Bagian atas juga dapat difungsikan sebagai tempat penyimpanan barang.

Adaptasi bentuk desain baru dengan acuan rumah adat Suku Lom

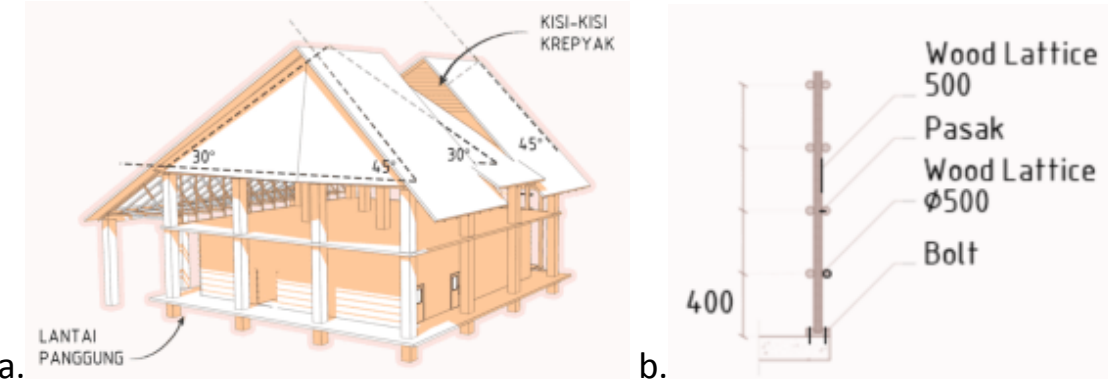

Gambar 16.a. Implementasi Bentuk Atap Dasar, b. Detail Dinding Kayu Sumber: Dokumentasi Pribadi, 2021

Rumah adat Suku Lom memakai atap tropis dan mempunyai sudut kemiringan antara $30^{\circ}-45^{\circ}$. Dalam implementasi desain pada proyek ini, menggunakan dua sudut acuan yaitu $30^{\circ}$ dan $45^{\circ}$. Pada bagian depan dan belakang atap menggunakan dua sudut yang berbeda, lalu bagian tengah menggunakan sudut yang sama, sehingga menghasilkan bentuk celah dari perbedaan tersebut yang dapat dimanfaatkan menjadi pengudaraan alami. Pada lantai mengikuti seperti bentuk Suku Lom yaitu lantai panggung dan dinding juga menggunakan material kayu.

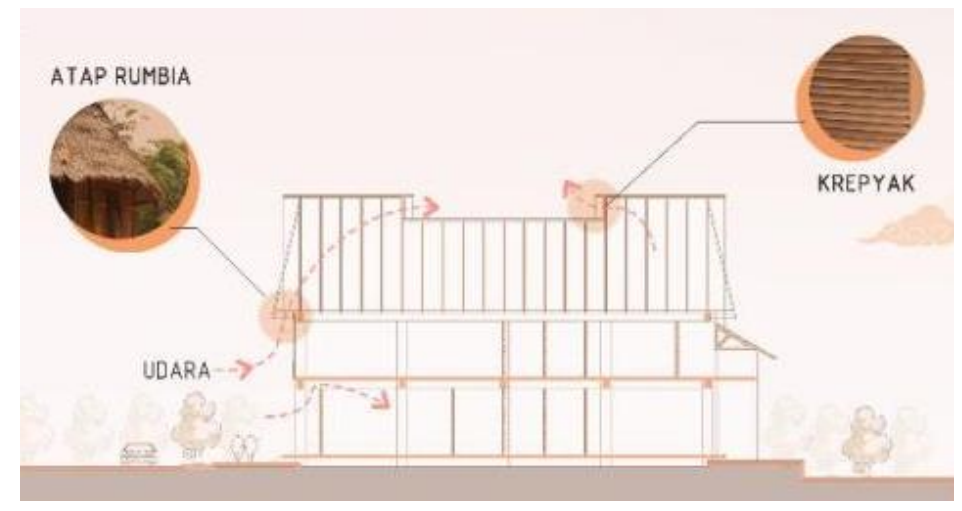

Gambar 17. Ventilasi Alami Bekerja pada Bangunan Sumber: Dokumentasi Pribadi, 2021

Konsep desain ventilasi atau pengudaraan pada perancangan ini adalah menggunakan pengudaraan alami, dan mengurangi penggunaan ventilasi buatan. Udara dapat bergerak bebas di lantai dua dengan melalui bagian depan, lebih tepatnya bagian bawah dari atap rumbia, lalu udara dapat naik dan keluar dari krepyak. Pada lantai satu, udara juga dapat bergerak dari antara dinding dan balok. 


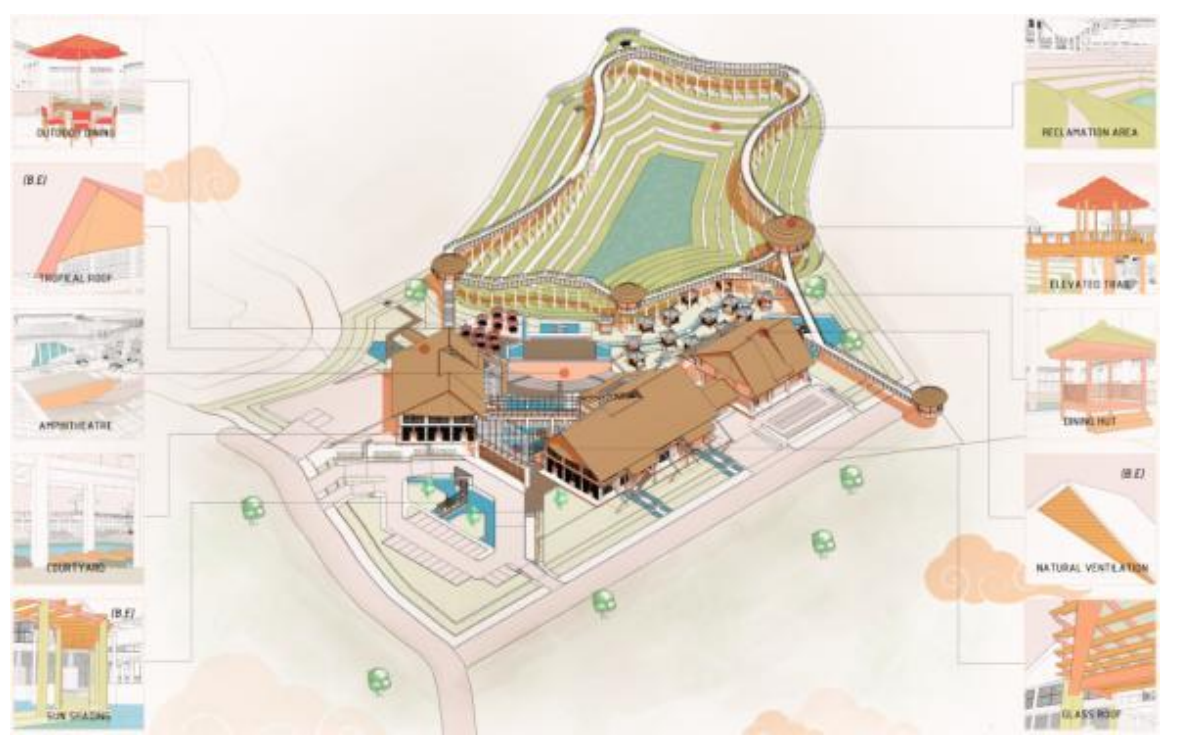

Gambar 18. 3D Massa Bangunan dan Konsep Penerapan Arsitektur Tropis Sumber: Dokumentasi Pribadi, 2021

Pada gambar diatas, terlihat bagaimana perancangan ini menggunakan atap tropis, memakai krepyak untuk pengudaraan alami, pemakaian sun shading, dan menambahkan courtyard untuk memisah kedua bangunan yang bersebelahan. Desain perancangan ini juga meminimalisir penggunaan material kayu dan menggunakan atap rumbia. Area makan outdoor pada perancangan ini dipisah menjadi dua bagian, yaitu dining hut, sebagai area makan yang lebih privasi dan outdoor dining, area makan yang lebih publik dan bebas. Area makan dibuat berundak agar mempunyai pemandangan langsung ke arah area reklamasi tambang. Selain itu, terdapat elevated trails yang menjadi tempat edukasi sekaligus rekreasi, elevated trails tersebut mengitari area reklamasi tambang timah, dan mempunyai pemandangan sekitar yaitu area bekas tambang timah, tambak udang yang sebelumnya adalah area bekas tambang timah, dan tropical rainforest.

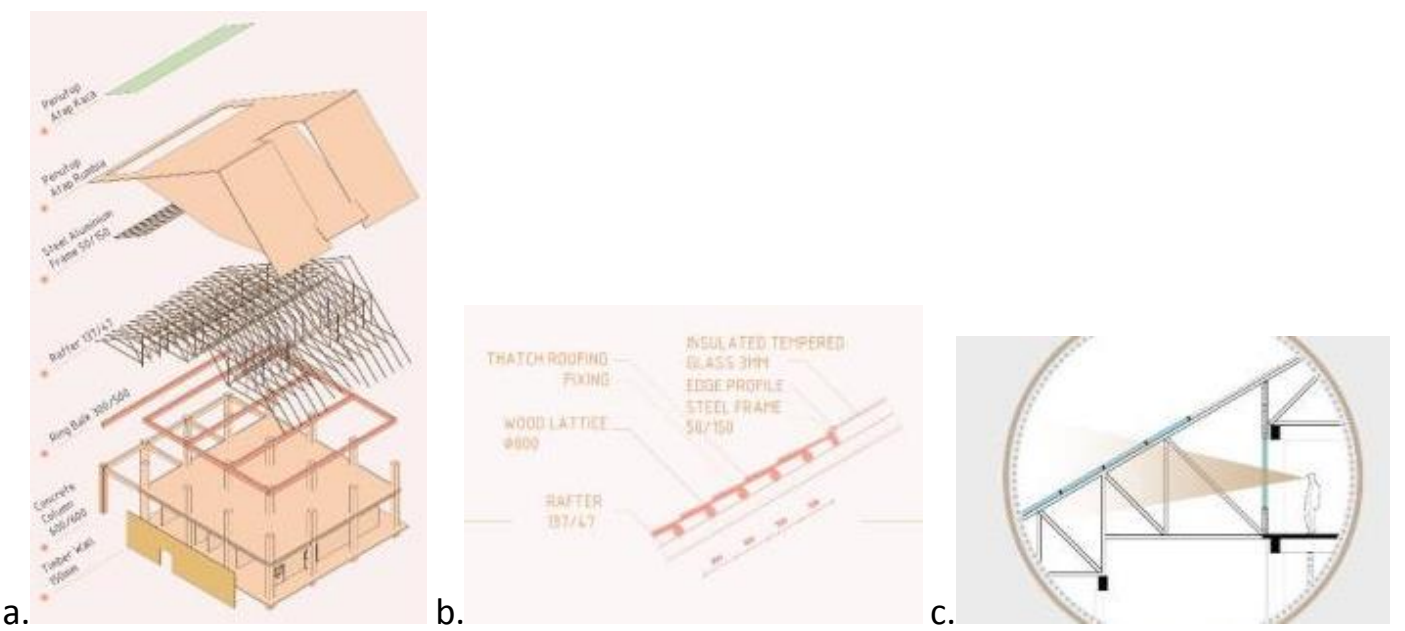

Gambar 19.a. Struktur Bangunan, b. Detail Struktur Atap, c. Ilustrasi Penggunaan Atap Kaca

Sumber: Dokumentasi Pribadi, 2021

Desain perancangan ini menggunakan atap rumbia dengan struktur kayu dan dikombinasikan dengan atap kaca agar pemandangan dari lantai dua tidak terhalang. Gambar (c.) mengilustrasikan bagaimana dari dalam bangunan pada lantai dua, orang tetap dapat melihat 
kearah luar. Gambar (b.) merupakan gambar detail struktur atap rumbia yang dikombinasikan dengan atap kaca, kedua penutup atap tersebut bertumpu di kuda-kuda atap.

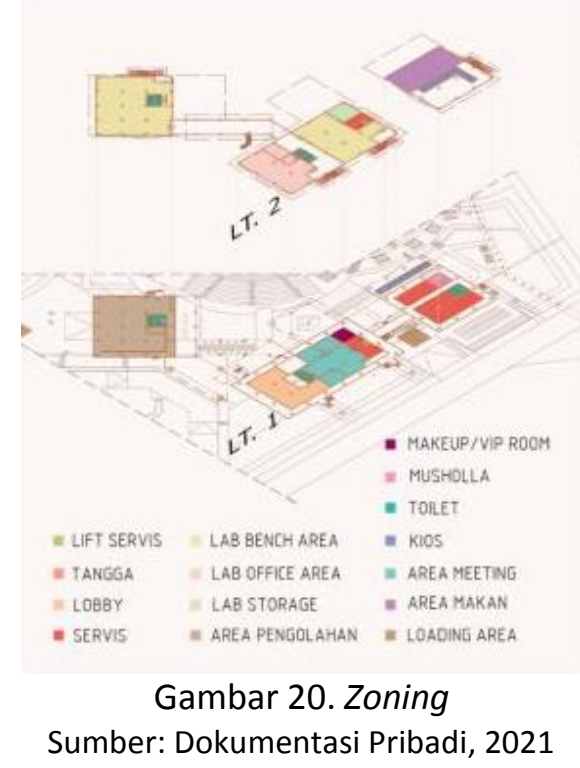

Gambar diatas merupakan gambar bagaimana penempatan ruang-ruang pada perancangan ini. Bagian depan bangunan terdapat lobby dan area pengolahan tailing menjadi batako. Bagian belakang dipakai menjadi area servis, dan tiap bangunan mempunyai toilet sehingga menjangkau pengguna.

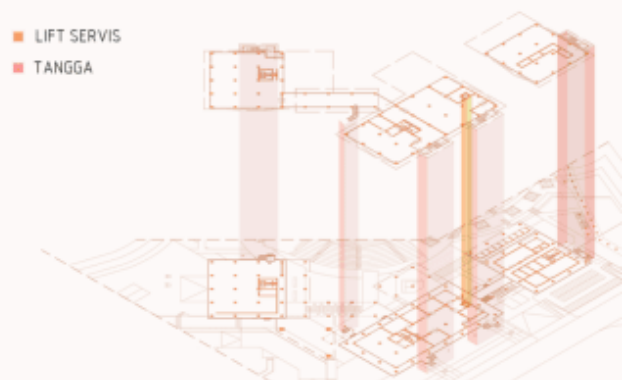

Gambar 21. Sirkulasi Vertikal

Sumber: Dokumentasi Pribadi, 2021

Sirkulasi vertikal yang digunakan untuk umum menggunakan tangga. Tangga pada desain perancangan ini diletakkan diluar, karena peletakannya berada diluar maka dapat berfungsi sebagai tangga kebakaran. Terdapat satu lift yang digunakan untuk kegiatan servis.

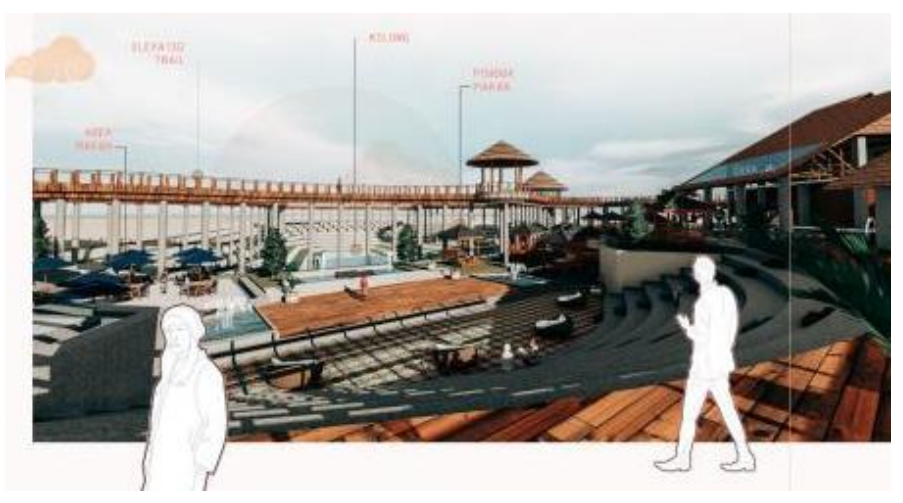


Gambar 22. Amphitheatre Menghadap Area Reklamasi Tambang Sumber: Dokumentasi Pribadi, 2021

Amphitheatre berada di bagian belakang setelah melewati plaza dari arah depan. Amphitheatre mempunyai pemandangan ke arah area reklamasi tambang, maka panggung mempunyai latar belakang area reklamasi tambang dan terlihat warna air kolong. Elevated trail menjadi batas antara area reklamasi tambang dengan amphitheatre. Area makan outdoor dapat langsung melihat ke arah amphitheatre selain pemandangan area reklamasi tambang. Berikut adalah gambar-gambar perspektif lainnya.

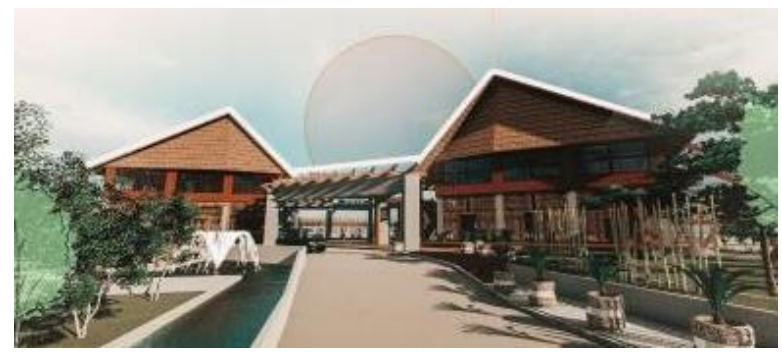

Gambar 23. Tampak Depan Bangunan

Sumber: Dokumentasi Pribadi, 2021

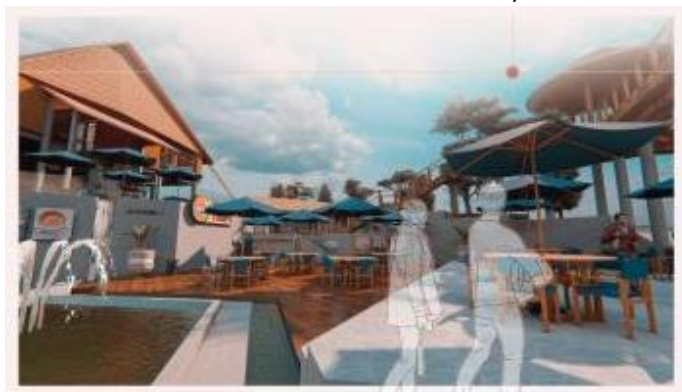

Gambar 24. Area Makan

Sumber: Dokumentasi Pribadi, 2021

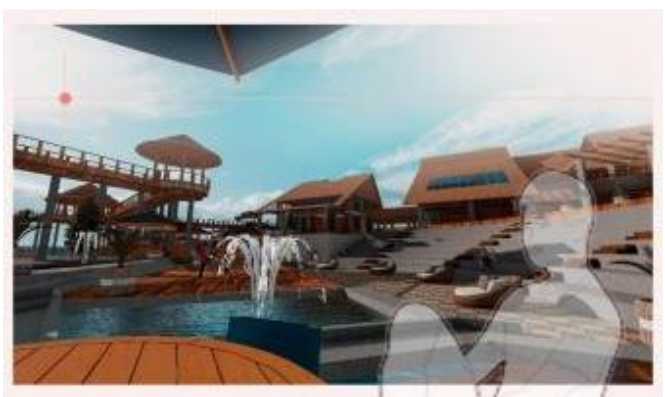

Gambar 25. Area Makan Menghadap Amphitheatre Sumber: Dokumentasi Pribadi, 2021

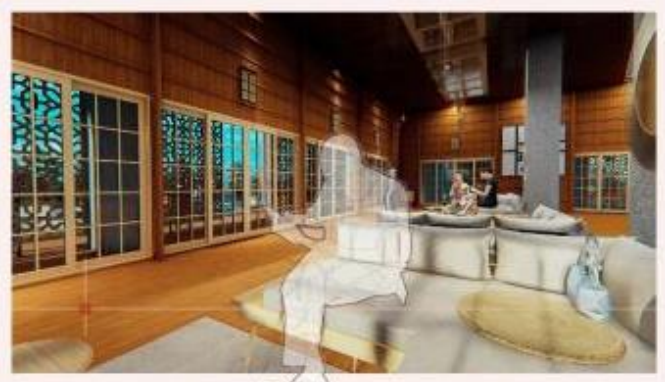

Gambar 26. Interior Lobby

Sumber: Dokumentasi Pribadi, 2021 


\section{KESIMPULAN DAN SARAN}

\section{Kesimpulan}

Hasil dan solusi yang didapatkan untuk menanggapi salah satu limbah kegiatan tambang, yaitu tailing, dengan mengusulkan perencanaan tempat proses pengolahan tailing menjadi batako, dan tempat konservasi tailing. Selain itu, menjadi tempat rekreasi dan edukasi dimana terdapat elevated trails yang mengitari area reklamasi tambang timah dengan pemandangan sekitar terdapat area bekas tambang timah, tambak udang yang sebelumnya merupakan bekas tambang dan terdapat tropical rainforest. Melakukan reklamasi pada area tambang timah, menerapkan sistem teras bangku setinggi 8 meter dengan tinggi 1 meter tiap terasnya dan sisa 5 meter adalah kolam. Bidang olah pada teras tersebut ditanam rumput pionir.

Penerapan pendekatan desain melalui arsitektur tradisional setempat yang diadaptasi ke bentuk desain baru, dapat terlihat dari pemakaian atap rumbia, memaksimalkan ventilasi alami, dan arsitektur tradisional mempunyai bentuk atap tropis. Bentuk arsitektur tropis pun pada desain perancangan ini dapat terlihat dari penggunaan sun shading. Dengan adanya bangunan ini diharapkan dapat menjadi contoh dalam menangani limbah kegiatan tambang dan bentuk adaptasi desain baru berdasarkan acuan arsitektur tradisional setempat.

\section{Saran}

Untuk selanjutnya terkait dengan kemungkinan desain lanjutan adalah pada proses perancangan dapat menambahkan penggunaan software untuk menguji bagaimana keadaan panas dalam kinerja bangunan tersebut dan seberapa banyak diperlukan pengudaraan buatan yang diperlukan, karena dalam penerapan desain ini bermaksud untuk memaksimalkan pengudaraan alami dan mengurangi pengudaraan buatan. 


\section{REFERENSI}

Ai Dariah, A. Abdurachman dan D. Subardja. (2010). Reklamasi lahan eks-penambangan untuk perluasan areal pertanian. Jurnal Sumberdaya Lahan, Vol. 4 No.1. Balai Besar Litbang Sumberdaya Lahan Pertanian, Bogor.

Direktorat Jenderal Pengendalian Pencemaran dan Kerusakan Lingkungan. (2016). Petunjuk Teknis Pemulihan Kerusakan Lahan Akses Terbuka Akibat Kegiatan Pertambangan. Dikutip tanggal $29 \quad$ Juni 2021, dari https://ppkl.menlhk.go.id/website/silat/filebox/14/181101064336Pedoman\%20Pemulih an\%20Lahan\%20\%20Akses\%20Terbuka.pdf.

Janawi. (2015). Agama Adat Suku Mapur Bangka: Studi tentang Sistem Kepercayaan dan Budaya Orang Lom. Disertasi Pascasarjana, UIN Sunan Kalijaga Yogyakarta.

Riogilang, H. dan Halimah Masloman. (2009). Pemanfaatan Limbah Tambang Untuk Bahan Konstruksi Bangunan. EKOTON Vol. 9 No.1: 69-73, April 2009.

Sandy, B. D. A., Guskarnali, G., \& Mahardika, R. G. (2019). ANALISIS UJI KUAT TEKAN DAN UJI DAYA SERAP AIR PADA BATAKO DARI PEMANFAATAN TAILING LAHAN BEKAS PENAMBANGAN TIMAH. PADURAKSA: Jurnal Teknik Sipil Universitas Warmadewa, 8(2), 213-221.

Sutono, S., Haryati, U., \& Agus, F. (2020). Karakteristik Tanah Dan Strategi Rehabilitasi Lahan Bekas Tambang Timah Di Provinsi Kepulauan Bangka Belitung. Jurnal Sumberdaya Lahan, 12(2), 99.

Syachroni, S. H., Rosianty, Y., \& Samsuri, G. S. (2019). DAYA TUMBUH TANAMAN PIONIR PADA AREA BEKAS TAMBANG TIMAH DI KECAMATAN BAKAM, PROVINSI BANGKA BELITUNG. Sylva, 7(2), 78-97. 